\title{
A Influência dos Valores Humanos no Compromisso Religioso
}

\author{
Walberto Silva dos Santos ${ }^{1}$ \\ Universidade Federal do Ceará \\ Valeschka Martins Guerra \\ Universidade Federal do Espírito Santo \\ Jorge Artur Peçanha de Miranda Coelho \\ Universidade Federal de Alagoas \\ Valdiney Veloso Gouveia \\ Luana Elayne Cunha de Souza \\ Universidade Federal da Paraíba
}

\begin{abstract}
RESUMO - A presente pesquisa analisou a relação entre o compromisso religioso e os valores humanos. Dois estudos específicos foram realizados. No primeiro participaram 535 estudantes, com idade média de 15,5 anos $(D P=3,24)$, a maioria do sexo feminino $(63,1 \%)$. No segundo, participaram 431 estudantes, com idade média de 15,4 anos $(D P=3,29)$, a maioria do sexo feminino (59\%). As hipóteses propostas foram corroboradas, indicando uma relação direta entre o compromisso religioso e os valores sociais, assim como uma relação inversa estabelecida com os valores de experimentação. Um efeito de supressão foi observado dos valores normativos sobre os valores de existência, sugerindo uma maior complexidade na interação entre os valores como explicadores do compromisso religioso.
\end{abstract}

Palavras-chave: Valores humanos, religiosidade; crenças; compromisso religioso.

\section{The Influence of Human Values on Religious Commitment}

\begin{abstract}
In the current research the relation between religious commitment and human values was analyzed. Two studies were conducted. In Study 1, 535 school and university students took part, with a mean age of 15.5 years $(S D=3.24)$, mostly women (63.1\%). In Study 2, participants were 431 school and university students, with a mean age of 15.4 years $(S D=3.29)$, mostly women (59\%). Proposed hypotheses were corroborated, indicating a direct relation between religious commitment and social values, as well as an opposite relation established with experimentation values. A suppression effect was observed from normative values on existence values, suggesting a higher complexity in the relation established among values as predictors of religious commitment.
\end{abstract}

Keywords: Human values; religiosity; beliefs; religious commitment.

“A existência sem um sistema de valores é patogênica. O ser humano necessita de uma trama de valores, de uma filosofia de vida, de uma religião ou de um substitutivo da religião de acordo com o qual viva e pense" (Maslow, 1983, p. 271).

Questões existenciais (por exemplo, quem é o homem, de onde veio) estão na base de diferentes religiões (Hellern, Notaker \& Gaarder, 2000). Neste sentido, a religião se constitui enquanto fenômeno cultural, social e histórico que se desenvolve na experiência de vida em comunidade. Crenças e costumes religiosos influenciam marcadamente a formação de sistemas de valores morais, sociais e, inclusive, políticos e econômicos (Basáñes \& Moreno, 1994).

Diferentes definições de religião podem ser encontradas na literatura. Hellern et al. (2000, p. 17) apresentaram algumas destas, tais como a de Schleiermacher, que a compreende como "um sentimento ou uma sensação de absoluta dependência", e a de Tiele, quando diz que a "religião significa a

1 Endereço para correspondência: Universidade Federal do Ceará UFC, Centro de Humanidades - Campus Benfica, Departamento de Psicologia. Avenida da Universidade, 2762. Fortaleza, CE, Brasil. CEP 60020-180. Tel/Fax:+55 (85) 3366-7723 relação entre o homem e o poder sobre-humano no qual ele acredita ou do qual se sente dependente". Nestas definições, é visível uma convergência de ideias acerca da dependência do homem em relação a um ser supremo e a necessidade de seguir determinadas crenças.

Cabe ainda considerar que, muitas vezes, os termos "religião" e "religiosidade" são usados como equivalentes, levando à ideia de que a religiosidade é um componente exclusivo da religião. Desta maneira, apenas possuiria religiosidade o indivíduo comprometido com uma forma institucional de religião, isto é, com uma religião organizada (Mendonça, 1998). Entretanto, crer em um deus pessoal ou numa realidade transcendente, a importância atribuída a um deus na vida, a obtenção de consolo na religião e ter momentos de oração ou contemplação, todos estes traços e atitudes referem-se ao que se denomina de religiosidade. Ser religioso pode implicar apenas uma orientação axiológica, embora o indivíduo não pertença ou não se sinta atraído por qualquer religião institucional (Cohen \& Hill, 2007). A religião, por sua vez, no sentido institucional, deve ser entendida como uma forma explícita, organizada e reconhecível de crenças e práticas, com doutrina e ética peculiares a determinado grupo social (Mendonça, 1998). 
Considerando a religião e religiosidade como centrais na vida das pessoas, justifica-se conhecê-la, identificando seus antecedentes. Assim, a presente pesquisa buscou precisamente estudar a relação entre o compromisso religioso e os valores humanos, utilizando como base a teoria funcionalista dos valores (Gouveia, 2003; Gouveia, Milfont, Fischer \& Coelho, 2009). A seguir, serão apresentadas considerações mais detalhadas sobre tais construtos.

\section{Compromisso religioso}

A religiosidade, enquanto construto tem sido pensada tanto como um fenômeno multidimensional como unidimensional (Schwartz \& Huismans, 1995). Segundo Roof (1979), é possível considerá-la a partir da unidimensionalidade quando: (1) se pretende observar sua relação com atitudes culturais ou valores humanos, (2) há um mesmo conjunto de hipóteses para diferentes religiões e (3) as amostras estudadas são da população geral, que é heterogênea. Para compreendê-la como multidimensional, faz-se necessário identificar seus componentes, conceituá-los e operacionalizá-los. A religiosidade ainda pode ser considerada como um valor humano e, por conseguinte, ser utilizada em tipologias que pretendam contemplar os valores básicos ou universais (Gouveia, 2003; Roccas, 2005; Schwartz, 2001).

Allport (1950) afirma que as pessoas usam a religião de duas formas: uma madura, cuja vivência é dinâmica, de mente aberta e capaz de manter relações entre as inconsistências; e outra imatura, que é auto-provedora e que geralmente representa os estereótipos negativos que se tem sobre a religião. Estas formas serviram de base para sua proposta de religiosidade intrínseca e extrínseca (Fuller, 2008; Öner-Özkan, 2007). A intrínseca corresponde à crença profunda na qual o indivíduo encontra a estrutura fundamental da sua existência, que dá significado à vida e em termos da qual tudo compreende; e a extrínseca, a religião do conforto e da convenção social, constituindo um elemento auto-suficiente que satisfaz o indivíduo (Allport, 1950).

De modo análogo, Allen e Spilka (1967) sugerem que os indivíduos formulam e estruturam suas crenças religiosas com base em dois tipos específicos de religiosidade, denominadas de compromissada e consensual. A compromissada apresenta-se como uma opção para a resolução de conflitos pessoais e situacionais, pois permite aos indivíduos utilizarem uma perspectiva abstrata e filosófica, na qual as muitas ideias religiosas têm significado claro, são abertas e flexíveis, podendo-se relacionar a religião com as atividades diárias. A consensual resultaria em uma visão superficial e conformista da vida, sendo concreta e restritiva, conformando-se aos valores e aos ideais tradicionais, mas estes são vagos, indiferenciados, neutralizados ou adotados de modo seletivo (Lotufo Neto, 1997).

Glock (1962; Glock \& Stark, 1966), por outro lado, estuda a religiosidade com base em um modelo multidimensional. Sua pesquisa tem sido considerada um passo fundamental na evolução das medidas de compromisso religioso. Pare este autor, a religiosidade apresenta uma estrutura composta por cinco fatores básicos: (1) a ex- periência religiosa vivenciada por uma pessoa; (2) a freqüencia das práticas religiosas por parte dos membros de uma determinada religião; (3) as convicções religiosas e sua consistência (4) o conhecimento acerca do sistema de crenças da religião confessada; (5) e as conseqüências éticas do envolvimento religioso.

A sistematização deste conjunto de componentes pode ser denominada de compromisso religioso, sendo tais fatores considerados fundamentais na elaboração do Índice de Compromisso Religioso (Santos, 2008) utilizado no presente estudo.

Santos (2008) concebe o compromisso religioso como a relação entre um conjunto de variáveis ou indicadores que envolvem aspectos centrais na expressão deste compromisso, tais como: a) o nível de religiosidade ou a percepção do quanto se é religioso; b) a freqüência às reuniões religiosas; c) a afiliação religiosa; e d) as crenças e as práticas religiosas, representadas por um conjunto de pensamentos e ações específicos de cada grupo religioso. Estes componentes diversos têm sido utilizados individualmente nos estudos que buscam conhecer a relação do compromisso religioso com os valores humanos.

\section{Valores humanos}

Os valores humanos são estudados com base em diferentes perspectivas. Referências sobre o tema podem ser encontradas em campos distintos, como filosofia, antropologia, sociologia e psicologia (Gouveia, 2003). Na psicologia e, mais precisamente, na psicologia social, as prioridades axiológicas têm sido amplamente exploradas, provavelmente pelo papel importante que exercem no processo seletivo das ações humanas (Rokeach, 1973). De fato, pesquisas sugerem a importância dos valores devido à sua forte associação com diversos construtos, tais como a religiosidade (Schwartz \& Huismans, 1995), consumo de drogas (Coelho Júnior, 2001) e comportamentos anti-sociais (Pimentel, 2004).

Rokeach é, provavelmente, um dos autores que mais contribuiu para os estudos recentes sobre valores (Gouveia et al., 2009). De acordo com Rokeach (1973, p. 5), um valor pode ser definido como "a crença duradoura de que um modo específico de comportamento ou estado final de existência é pessoal ou socialmente preferível a um modo de comportamento ou estado final de existência oposto ou inverso". Em síntese, os valores podem ser entendidos como crenças prescritivas/proscritivas que permitem aos indivíduos julgarem objetos ou ações como desejáveis, indesejáveis, recomendáveis ou reprováveis.

O modelo desenvolvido por Shalom H. Schwartz é, na atualidade, a principal referência no campo dos valores. De acordo com este autor, os valores são "metas desejáveis e trans-situacionais, que variam em importância, que servem como princípio na vida de uma pessoa ou de outra entidade social" (Schwartz, 2001, p. 55). Apesar desta proposta teórica desfrutar popularidade no meio científico, um modelo mais recente (Gouveia, 2003) tem sido identificado como mais parcimonioso na explicação de condutas e atitudes (Boer, 2009; Guerra, 2009). 


\section{A teoria funcionalista dos valores humanos}

O modelo de valores proposto por Gouveia (2003) baseia-se nas funções dos valores. De acordo com Gouveia et al. (2009), os valores são critérios de orientação que guiam as ações do homem e expressam suas necessidades básicas. Sua concepção de valores inclui três suposições teóricas, a saber: (1) assume a natureza benevolente do ser humano; (2) os valores são representações cognitivas das necessidades individuais, demandas da sociedade e instituicionais, que restringem os impulsos pessoais e asseguram um ambiente estável e seguro; e (3) todos os valores são terminais, ou seja, expressam um propósito em si, sendo definidos como substantivos. Seu modelo tem como foco principal duas funções consensuais dos valores: eles guiam as ações do homem (tipo de orientação) e expressam suas necessidades (tipo de motivador). Segundo este autor, todos os valores podem ser classificados em termos materialistas (pragmáticos), que referem-se a ideias práticas e uma orientação para metas, ou idealistas (abstratos), que referem-se a princípios e ideais abstratos e uma orientação universal.

Tais dimensões podem ser combinadas em uma estrutura três por dois, ou seja, com três critérios de orientação (social, central e pessoal) e dois tipos de motivadores (materialistas e idealistas). A partir das interações dos valores ao longo dos eixos, são identificadas seis sub-funções distribuídas equitativamente nos critérios de orientação social (interativos e normativos), central (suprapessoal e existência) e pessoal (experimentação e realização). Deste modo, os tipos de motivadores são representados por meio de três sub-funções cada: no tipo materialista localizam-se os valores de existência (estabilidade pessoal, saúde e sobrevivência), realização (êxito, poder e prestígio) e normativos (obediência, religiosidade e tradição), e no idealista, os suprapessoais (beleza, conhecimento e maturidade), de experimentação (emoção, prazer e sexo) e interativos (afetividade, apoio social e convivência). Ao longo dos anos, diversos estudos têm corroborado a adequabilidade deste modelo por meio dos parâmetros psicométricos e de sua relação com outros construtos (Gouveia et al., 2009).

\section{Valores e religiosidade}

Diversos estudos procuraram estabelecer a relação entre valores e religiosidade em diferentes grupos culturais e religiosos (Barnea \& Schwartz, 1994; Saroglou, Delpierre \& Dernelle, 2004). Em um estudo realizado por Menéndez (2007) com participantes europeus em países de maioria católica, correlações entre indicadores religiosos e valores de individualização foram encontrados: o valor liberdade correlacionou-se negativamente com o nível de confiança na igreja $(r=-0,49, p<0,01)$, a importância da religião $(r=$ $-0,46, p<0,01)$, fé religiosa $(r=-0,47, p<0,01)$ e a importância de Deus na vida do participante $(r=-0,43, p<0,01)$.

Um estudo realizado por Schwartz e Huismans (1995) em quatro países apresentou associações positivas com tradição $(r=0,54, p<0,01)$ e conformidade $(r=0,30, p<0,01)$, e negativas com hedonismo $(r=-0,39, p<0,01)$, estimulação $(r=-0,34, p<0,01)$ e autodireção $(r=-0,33, p<0,01)$.
Renner, Salem e Alexandrowicz (2004), procurando desenvolver o Questionário de Valores Austríacos, demonstraram que a religiosidade apresentou correlações diretas com os valores de harmonia com a comunidade $(r=0,23, p$ $<0,01)$, religiosidade $(r=0,78, p<0,01)$ e nacionalismo $(r=$ $0,32, p<0,01)$, e uma correlação inversa com hedonismo $(r$ $=-0,17, p<0,01)$. Demonstraram ainda que pontuações altas em valores religiosos e nacionalismo e baixa em hedonismo explicam atitudes religiosas.

Uma meta-análise realizada por Saroglou et al. (2004), com 21 estudos de 15 países $(N=8.551)$, demonstrou que participantes das três religiões monoteístas estudadas tenderam a atribuir importância a valores que refletem conservação (tradição e conformidade), importância limitada a autotranscendência (benevolência, mas não universalismo) e baixa importância a valores que indicam abertura à mudança e autorealização (auto-direção, hedonismo, estimulação e, de forma menos sistemática, poder e realização).

Em estudo realizado com 144 estudantes de Moçambique, demonstrou-se que os participantes cristãos apresentaram pontuações maiores em valores de realização, universalismo, benevolência e tradição quando comparados a participantes muçulmanos. Com base nestes resultados, Costa e Goodwin (2006) concluíram que esta diferença demonstra uma falta de valores representativos na população muçulmana, que deve apoiar valores não incluídos na medida.

Tais resultados sugerem que diferentes comunidades culturais podem apresentar relações diferentes entre as prioridades valorativas e a religiosidade. De acordo com Cohen e Hill (2007), grupos religiosos podem ser considerados como comunidades culturais, pois religiões são sistemas que enfatizam valores e crenças específicos, tais como obediência à autoridade, crença nas leis da natureza, respeito à familia e justiça social. Não se encontrou qualquer estudo acerca do compromisso religioso e sua relação com valores no contexto brasileiro.

Segundo Roccas (2005), é possível obter uma melhor compreensão do que significa ser religioso ou não religioso mediante o estudo do relacionamento entre religiosidade e valores. Entre religiões monoteístas, o padrão de correlação entre religiosidade e valores apresenta-se de forma consistente: pessoas comprometidas com grupos religiosos atribuem maior importância a valores que expressam evitação de incertezas e menor importância a valores que expressam desejos hedonistas e independência.

Em estudo que procurou testar qual o melhor preditor de religiosidade, entre valores e traços de personalidade, Saroglou e Muñoz-Garcia (2008) observaram que os valores explicaram $22 \%$ da variância de religiosidade e $12 \%$ de espiritualidade. A inclusão de traços de personalidade não aumentou significativamente a porcentagem de variância explicada. Tais resultados replicaram um estudo semelhante realizado por Roccas, Sagiv, Schwartz e Knafo (2002) com estudantes israelenses.

Tais estudos demonstram a forte associação entre a religiosidade e os valores humanos. Se considerarmos a religiosidade como um dos fatores constituintes do compromisso religioso, os valores humanos podem ser considerados como variáveis relevantes na predição deste compromisso. No entanto, nenhum estudo foi encontrado na literatura acerca da associação entre tais construtos no Brasil, sugerindo a relevância do presente estudo. 


\section{Estudo 1}

O presente estudo compreendeu um delineamento correlacional ex post facto, tendo como objetivo principal conhecer a relação entre os valores humanos, considerados como variáveis independentes, e o índice de compromisso religioso, considerado como variável dependente. Levando-se em conta a literatura acerca da relação entre religiosidade e valores, foram formuladas duas hipóteses principais: 1) valores sociais (normativos e interativos) apresentarão correlação positiva com o compromisso religioso; e 2) valores de experimentação apresentarão correlação negativa com o compromisso religioso. Como os valores de realização, de orientação pessoal, assim como aqueles de existência e suprapessoais, de orientação central, não tem apresentado correlações consistentes com a religiosidade, nenhuma hipótese foi formulada a respeito.

\section{Método}

\section{Participantes}

Participaram 535 estudantes dos ensinos fundamental $(38,4 \%)$, médio $(38,5 \%)$ e superior $(22,9 \%)$, distribuídos entre instituições de ensino público $(52,8 \%)$ e privado $(47,2 \%)$. Estes apresentaram idade média de 15,5 anos ( $D P$ $=3,24$; amplitude de 10 a 22 anos), sendo a maioria do sexo feminino $(63,1 \%)$. Quanto à religião, $61,4 \%$ deles se confessaram católicos, $24,1 \%$ evangélicos, $8,1 \%$ sem religião e $6,4 \%$ disseram-se espíritas ou pertencentes a outros grupos religiosos (por exemplo, mórmon, budista, judeu).

\section{Instrumentos}

Os participantes responderam a um questionário composto por um conjunto de diferentes instrumentos, descritos a seguir:

Questionário dos Valores Básicos - QVB (Gouveia, 2003). Este instrumento é composto por 18 itens (valores básicos), distribuídos nas seis subfunções: experimentação, realização, existência, suprapessoal, interacional e normativa. Para respondê-lo, o participante deve ler a lista de valores e indicar em que medida cada um deles é importante como um princípio que guia sua vida. Para tanto, utiliza escala de resposta com os seguintes extremos: $\mathbf{1}=$ Totalmente não Importante e $\mathbf{7}=$ Totalmente Importante.

Os diferentes indicadores do compromisso religioso são medidos pelas seguintes escalas:

Escala de Práticas Religiosas (Meira, Gouveia, Socorro, Oliveira \& Silva Filho, 2001). Considerou-se um versão composta por 14 itens, distribuídos entre práticas católicas (6 itens; por exemplo, Rezo o terço; Assisto à missa), espíritas (4 itens; por exemplo, Leio livros psicografados; Procuro desenvolver meus dons mediúnicos) e protestantes (4 itens; por exemplo, Prego o evangelho para outras pessoas; Dou o dízimo). Todos os itens foram respondidos em escala de cinco pontos, tipo Likert, com os extremos 1 = Nunca e $\mathbf{5}$ = Sempre.

Escala de Crenças Religiosas (Andrade, Gouveia, Jesus, Santos \& Andrade, 2001). Esta medida compõe-se de 17 itens, que contemplam crenças católicas (6 itens; por exemplo, Imagens de santos devem ser respeitadas; $\dot{E}$ importante fazer a primeira comunhão), espíritas (6 itens; por exemplo, É possivel a comunicação com pessoas que já faleceram; Jesus foi um espírito evoluído que passou pela terra) e protestantes (5 itens; por exemplo, A vocação para o trabalho é um dom divino; Jesus Cristo é o único intercessor entre Deus e o homem). Com o fim de respondê-los, o participante utiliza uma escala de sete pontos, do tipo Likert, com os seguintes extremos: $\mathbf{1}=$ Discordo totalmente e $\mathbf{7}=$ Concordo totalmente.

Caracterização da Amostra. Finalmente, além dos itens para caracterização da amostra (por exemplo, sexo, idade, estado civil), foram consideradas as seguintes perguntas: $\mathrm{Em}$ que medida você se considera religioso?, respondida em uma escala de cinco pontos, variando de $\mathbf{0}=N a d a$ a $\mathbf{4}=$ Muito; e Com que freqüência você vai às reuniões da sua religião?, respondida por meio de uma escala de freqüência, variando de $\mathbf{0}=$ Nunca a $\mathbf{7}=$ Sempre. Finalmente, perguntou-se qual a religião do participante.

Os indicadores do compromisso religioso tiveram suas pontuações transformadas e combinadas em um único escore, variando entre 0 (baixo compromisso) e 1 (alto compromisso), segundo os procedimentos sugeridos por Santos (2008).

\section{Procedimento}

Os participantes responderam os questionários individualmente, ainda que em ambiente coletivo de sala de aula. Os instrumentos foram distribuídos por seis aplicadores (dois homens e quatro mulheres), devidamente instruídos para controlar os fatores que pudessem comprometer as respostas. $\mathrm{Na}$ ocasião, as mesmas instruções foram dadas para todos os respondentes e os princípios éticos foram garantidos, solicitando a leitura e assinatura no termo de consentimento livre e esclarecido, onde enfatizava-se o caráter voluntário da participação e a garantia de que toda informação era confidencial. O tempo utilizado para preencher o instrumento não ultrapassou uma aula (50 minutos).

\section{Análise de dados}

Os dados resultantes foram inseridos no computador para as análises estatísticas, realizadas no programa $P A S W$ Statistics 18.0 for Windows (Pacote Estatístico para Ciências Sociais Versão 18.0 para Windows), mediante o qual foram realizadas correlações de ordem zero de Pearson. Testes de diferença entre correlações dependentes foram realizados no programa Excel 2007 for Windows. Um nível de significância (alfa) de 0,05 foi adotado para todas as análises. 
Tabela 1. Estudo 1: Correlações entre as sub-funções dos valores humanos e o índice de compromisso religioso

\begin{tabular}{lcccccc}
\hline & 1 & 2 & 3 & 4 & 5 & 6 \\
\hline 1. Compromisso religioso & - & & & & & \\
2. Normativa & $0,43^{* *}$ & - & & & & \\
3. Interacional & $0,19^{* *}$ & $0,21^{* *}$ & - & & & \\
4. Existência & 0,04 & $0,21^{* *}$ & $0,33^{* *}$ & - & & \\
5. Suprapessoal & 0,04 & $0,12^{* *}$ & $0,29 * *$ & $0,37^{* *}$ & - & - \\
6. Realização & $-0,02$ & 0,02 & $0,10^{*}$ & $0,28^{* *}$ & $0,19^{* *}$ & - \\
7. Experimentação & $-0,18^{* *}$ & $-0,18^{* *}$ & 0,8 & $0,15^{* *}$ & 0,70 & $0,17 *$ \\
\hline
\end{tabular}

Nota. $* p<0,05 ; * * p<0,01$.

\section{Resultados}

No que diz respeito ao teste de hipóteses, foram realizadas análises de correlação de Pearson (ver Tabela 1). Ambas subfunções dos valores sociais apresentaram correlações diretas com o compromisso religioso, corroborando a primeira hipótese, sendo a associação com os valores normativos significativamente maior do que com os interacionais, em um teste de diferença entre correlações dependentes, $t(532)=$ $4,83, p<0,001$. A mesma relação foi testada sem a presença do valor religiosidade como um dos integrantes da subfunção normativa, tendo os resultados permanecido significativos $(r$ $=0,28, p<0,001)$.

Com relação aos valores pessoais, apenas experimentação apresentou correlação com o compromisso religioso, sendo esta diferente da observada com valores de realização, $t$ $(532)=-3,77, p<0,001$. Tal resultado corroborou a segunda hipótese proposta. Os valores centrais não apresentaram correlação com o compromisso religioso.

\section{Discussão parcial}

Tendo-se em vista o objetivo do presente estudo - conhecer a relação entre os valores humanos e o compromisso religioso, considera-se que este foi alcançado. As duas hipóteses propostas foram corroboradas, replicando resultados prévios acerca da relação direta entre o compromisso religioso e os valores normativos, assim como da relação inversa estabelecida com os valores de experimentação (Menéndez, 2007; Saroglou et al., 2004; Schwartz \& Huismans, 1995).

Segundo Gouveia et al. (2009), valores normativos enfatizam a preservação de normas convencionais e do status $q u o$. Por outro lado, valores de experimentação enfatizam a busca de aventuras e prazer, associada a uma vida independente. Finalmente, os valores humanos se relacionam com o compromisso religioso, sendo estabelecidas relações coerentes com as predições baseadas na teoria funcionalista dos valores humanos. Portanto, este estudo apresenta a primeira evidência empírica da aplicação da teoria para compreender o compromisso religioso.

\section{Estudo 2}

Segundo Saroglou e Muñoz-Garcia (2008), devido à natureza correlacional dos estudos acerca dos valores e religião, conclusões não podem ser tiradas acerca da direção de uma possível causalidade. Estes autores sugerem que ambas as direções são possíveis. Ou seja, crenças religiosas podem influenciar a prioridade dada a valores específicos, assim como pessoas que endossam certos valores (i.e., tradição) em detrimento de outros (i.e., hedonismo) podem encontrar em práticas religiosas uma forma sistematizada de viver e organizar seus valores. Assim, o segundo estudo tem como objetivo verificar se as subfunções valorativas dos participantes influenciam seu compromisso religioso, replicando os resultados do primeiro estudo e utilizando análises de regressão múltipla.

Neste sentido, foram formuladas as seguintes hipóteses: 1) valores sociais (normativos e interativos) apresentarão associação positiva com o compromisso religioso; e 2) valores de experimentação apresentarão associação negativa com o compromisso religioso. Os valores de realização, existência e suprapessoais, não apresentaram associações com o compromisso religioso no Estudo 1, portanto nenhuma hipótese neste sentido foi formulada. No entanto, tais variáveis serão incluídas nas análises de regressão de forma a verificar se os resultados se repetem.

\section{Método}

\section{Participantes}

Participaram 431 estudantes com idade média de 15,4 anos $(D P=3,29$; amplitude 10 a 22 anos), a maioria do sexo feminino $(59 \%)$, católicos $(58,5 \%)$ e protestantes $(27 \%)$; alguns se confessaram espíritas $(2,1 \%)$, outros disseram pertencer a outro preceito religioso $(3,4 \%)$ e também tiveram os que disseram não ter qualquer religião $(9 \%)$. Tais participantes foram distribuídos em diferentes níveis escolares, a partir da $4^{a}$ série do ensino fundamental $(5 \%)$ até estudantes universitários $(19,6 \%)$. 


\section{Instrumentos e Procedimentos}

Os participantes responderam os mesmos instrumentos descritos no Estudo 1, lembrando: Escala de Práticas Religiosas (Meira et al., 2001), Escala de Crenças Religiosas (Andrade et al., 2001) e Questionário dos Valores Básicos (Gouveia, 2003). Incluíram-se também duas perguntas sobre a religiosidade dos participantes: (1) Em que medida você se considera religioso? Esta foi respondida em escala de cinco pontos, variando de $\mathbf{0}=$ Nada a $\mathbf{4}=$ Muito; e (2) Com que frequência você vai às reuniões de sua religião? Sua resposta foi dada por meio de uma escala de frequência, variando de $\mathbf{0}$ =Nunca a 7 = Sempre. Finalmente, foram incluídas perguntas demográficas (sexo, idade, escolaridade e religião).

A aplicação dos instrumentos foi realizada em escolas e universidades. Contou-se com a colaboração de três bolsistas de Iniciação Científica, que foram devidamente instruídos, evitando dar esclarecimentos de conteúdo das medidas. A todos os participantes foi informado que: (a) sua participação era voluntária, (b) não seria necessária sua identificação e (c) que o anonimato das informações obtidas seria assegurado, explicando que todos os dados seriam tratados estatisticamente no seu conjunto. Finalmente, foi solicitado aos participantes que assinassem um termo de consentimento livre e esclarecido, permitindo o uso das informações contidas no questionário. Em média, 40 minutos foram suficientes para concluir esta atividade.

\section{Análise de dados}

O programa PASW Statistics 18.0 for Windows (Pacote Estatístico para Ciências Sociais Versão 18.0 para Windows) foi utilizado para as análises de correlação e regressão. Testes de diferença entre correlações dependentes foram realizados no programa Excel 2007 for Windows. Um nível de significância (alfa) de 0,05 foi adotado para todas as análises.

\section{Resultados}

Análises de correlação foram realizadas, com o objetivo de replicar os resultados do Estudo 1. Como pode ser observado na Tabela 2, o índice de compromisso religioso apresentou correlações positivas com ambas as subfunções dos valores sociais, sendo a associação com valores normativos significativamente maior do que com os interacionais, em um teste de diferença entre correlações dependentes, $t$ (428) $=1,97, p<0,05$. Tal resultado corrobora a primeira hipótese proposta, replicando os achados do Estudo 1.

De forma similar ao Estudo 1, apenas a subfunção de experimentação dos valores pessoais apresentou correlação com o compromisso religioso, sendo esta diferente da observada com valores de realização, $t(428)=2,88, p<$ 0,01 . Tal resultado corroborou a segunda hipótese proposta, replicando os achados do Estudo 1. Novamente, os valores centrais não apresentaram correlação com o compromisso religioso.

Em seguida, as seis subfunções valorativas foram inseridas como variáveis independentes em uma análise de regressão múltipla, com método stepwise. Os resultados são descritos na Tabela 3.

O modelo encontrado explica $17 \%$ da variância do compromisso religioso. Valores normativos e interacionais apresentaram associação direta com o compromisso religioso, corroborando a Hipótese 1, enquanto os valores de experimentação apresentaram associação inversa com este índice, corroborando a Hipótese 2, juntamente com os de existência.

Tal padrão de associação entre os valores de existência e o compromisso religioso não era esperado, pois em ambos estudos, não foram observadas correlações significativas entre estas variáveis. A inserção de tais valores como preditores do compromisso sugerem um efeito de supressão. Uma variável supressora é definida por Tabachnick e Fidell (2008) como aquela que apresenta uma associação com uma variável independente (VI) de forma a controlar variâncias irrelevantes para a predição da variável dependente (VD), fazendo com que o valor do índice de associação da VI com a VD aumente. Tal efeito indica a relações complexas entre as variáveis independentes, i.e., os valores humanos, e o compromisso religioso. Identifica-se um efeito de supressão verificando os coeficientes de correlação e regressão entre as VIs (valores) e a VD (compromisso religioso). Os sinais que confirmam a supressão são: 1) o valor absoluto da correlação entre valores de existência (supressora) e compromisso (VD) deve ser menor que o peso b observado; e 2) sinais opostos são observados entre a correlação simples e o peso b da mesma variável em sua relação com o compromisso.

Tabela 2. Estudo 2: Correlações entre as sub-funções dos valores humanos e o índice de compromisso religioso

\begin{tabular}{lcccccc}
\hline & 1 & 2 & 3 & 4 & 5 & 6 \\
\hline 1. Compromisso religioso & - & & & & & \\
2. Normativa & $0,31^{* *}$ & - & & & & \\
3. Interacional & $0,21^{* *}$ & $0,39^{* *}$ & - & & & \\
4. Existência & 0,04 & $0,34^{* *}$ & $0,38^{* *}$ & - & & \\
5. Suprapessoal & $-0,02$ & $0,23^{* *}$ & $0,31^{* *}$ & $0,38^{* *}$ & - & \\
6. Realização & 0,00 & 0,07 & 0,09 & $0,23 * *$ & $0,17^{* *}$ & - \\
7. Experimentação & $-0,18^{* *}$ & $-0,04$ & $0,16^{* *}$ & $0,23 * *$ & $0,15^{* *}$ & $0,14^{* *}$ \\
\hline
\end{tabular}

Nota. $* p<0,05 ; * * p<0,01$. 
Tabela 3. Regressão múltipla do compromisso religioso

\begin{tabular}{ccccc}
\hline \multicolumn{1}{c}{ Preditores } & $\mathbf{R}_{\text {mudança }}^{2}$ & $\beta$ & $\boldsymbol{t}$ \\
\hline $\mathrm{R}^{2}=0,17 ; \mathrm{R}_{\text {Ajustado }}^{2}=0,16$ & & & \\
\hline Normativos & 0,10 & 0,29 & $5,87 * *$ \\
Experimentação & 0,03 & $-0,16$ & $3,43 * *$ \\
Interacionais & 0,02 & 0,19 & $3,70^{* *}$ \\
Existência & 0,02 & $-0,18$ & $3,49 * *$ \\
\hline
\end{tabular}

Nota. $* \mathrm{p}<0,05 ; * * \mathrm{p}<0,01$.

Devido ao fato de que todas as subfunções dos valores foram inseridas na regressão como possíveis preditoras, a identificação da subfunção que apresentou um efeito de supressão com os valores de existência foi feita mediante uma série de análises de regressão. Mediante estas análises foi possível identificar que o efeito de supressão ocorreu na relação entre os valores normativos e de existência. Os valores de existência apresentaram uma correlação próxima de zero com o compromisso religioso. A análise de regressão múltipla demonstrou que, apesar de não se correlacionar com compromisso, valores de existência entraram na equação com um sinal negativo quando inserido conjuntamente com os valores normativos, confirmando os dois critérios sugeridos por Tabachnick e Fidell (2008) para a existência de uma supressão.

\section{Discussão geral}

O presente estudo objetivou, principalmente, conhecer os valores que poderiam explicar o compromisso religioso. Estima-se que este propósito tenha sido alcançado. Não obstante, cabe assinalar algumas de suas limitações potenciais, particularmente no que diz respeito à amostra. Esta não foi aleatória, nem pode ser considerada representativa da população brasileira. Por ser uma amostra de conveniência (não-probabilística), não permite a generalização dos resultados. Além disso, a pouca representatividade de alguns grupos religiosos também pode ser considerada um viés desta pesquisa. No entanto, segundo o IBGE (2000), no Brasil observa-se a seguinte distribuição: católicos $(73,6 \%)$, protestantes $(15,4 \%)$, espíritas $(1,3 \%)$, umbandistas $(0,3 \%)$, pessoas de outras religiões $(1,8 \%)$ e que confessam não ter religião $(7,4 \%$,$) . Neste sentido, as amostras contempladas$ não discrepam tanto da realidade deste país e os estudos não objetivam a generalização dos resultados, mas unicamente conhecer as relações estabelecidas entre as variáveis propostas. A propósito, procura-se discutir a seguir os principais resultados.

\section{Valores preditores do compromisso religioso}

As hipóteses elaboradas no Estudo 1 foram corroboradas e replicadas no Estudo 2. O compromisso religioso se correlacionou positivamente com os valores sociais (normativos e interativos), resultado este observado em ambos os estudos e que corrobora pesquisas anteriores acerca da relação entre valores e religiosidade (Menéndez, 2007; Saroglou et al., 2004; Schwartz \& Huismans, 1995).

De forma coerente com tais resultados, os valores de experimentação, subfunção dos valores de orientação pessoal, apresentaram associações negativas com o compromisso religioso. Isso sugere que o indivíduo que apresenta um nível alto de compromisso religioso seria aquele que busca seguir as normas sociais, cumprindo suas atividades e deveres, que dão importância ao fato de fazerem parte de grupos sociais e religiosos, prezando pelo apoio encontrado nestes grupos e evitando a busca de prazer e aventura (Gouveia et al., 2009).

A associação negativa entre o compromisso religioso e os valores de existência observada no Estudo 2 não era esperada. Nesta relação, os valores normativos atuaram como variável supressora de variâncias irrelevantes para a predição do compromisso religioso, fazendo com que sua associação com os valores de existência aumentasse significativamente. Variáveis supressoras não são facilmente identificadas na literatura (Tachnick \& Fidell, 2008), sugerindo a relevância deste trabalho na observação de relações complexas estabelecidas entre valores e o compromisso religioso. Para a psicologia social, assim como para os estudos da psicologia da religião, a identificação de tal complexidade pode auxiliar na elaboração de novas pesquisas que considerem a interação entre os valores humanos associada a outros construtos.

A consistência das correlações apresentadas nesta pesquisa sugerem a importância dos valores humanos como preditores do compromisso religioso. Segundo Barnea e Schwartz (1994), a religião exerce influência marcante no ambiente. Neste sentido, a harmonia social estabelecida em sociedades religiosas pressupõe o compartilhamento de valores básicos. Segundo Costa e Goodwin (2006), a religião pode ser considerada um determinante de sistemas de valores diferenciados.

Finalmente, como os valores se revelam proeminentes para compreender diferenças individuais no compromisso religioso, sugere-se que, em pesquisas futuras que visem compreender antecedentes e consequentes deste compromisso, os valores humanos sejam considerados. Por exemplo, poderia-se analisar a relação dos participantes comprometidos com sua religiosidade com o desejo de apresentar condutas julgadas positivamente pelo grupo no qual estão inseridos, de forma a oferecer um modelo teórico dos comportamentos pró-sociais no contexto de diferentes denominações religiosas.

\section{Referências}

Allen, R., \& Spilka, B. (1967). Committed and consensual religion: A specification of religion prejudice relationships. Journal for the Scientific Study of Religion, 6, 191-206.

Allport, G. (1950). The individual and his religion. Nova York, NY: Macmillan.

Andrade, J., Gouveia, V., Jesus, G., Santos, W., \& Andrade, W. (2001). Escala de crenças religiosas: Elaboração e validação de construto [Resumo]. In Conselho Regional de Psicologia 13a Região PB/N (Ed.), $1^{\circ}$ Encontro Paraibano de Avaliação e Medida em Psicologia (p. 14). João Pessoa, PB: CRP. 
Barnea, M., \& Schwartz, S. (1998). Values and voting, Political Psychology, 19, 17-40.

Basáñes, M., \& Moreno, A. (1994). México en la Encuesta Mundial de Valores 1981-1990. In J. D. Nicolás \& R. Inglehart (Eds.), Tendencias mundiales de cambio en los valores sociales $y$ políticos (pp. 499-528). Madri: Fundesco.

Boer, D. (2009). Music makes people come together: Social functions of music listening for young people across cultures. Tese de Doutorado, Victoria University of Wellington, Wellington, Nova Zelândia.

Coelho Júnior, L. L. (2001). Uso potencial de drogas em estudantes do ensino médio: Suas correlações com as prioridades axiológicas. Dissertação de Mestrado, Universidade Federal da Paraíba, João Pessoa.

Cohen, A., \& Hill, P. (2007). Religion as culture: Religious individualism and collectivism among American Catholics, Jews, and Protestants. Journal of Personality, 75, 709-742.

Costa, P., \& Goodwin, R. (2006). The role of religion in human values: A case study. Journal of Beliefs and Values, 27, 341346.

Fuller, A. R. (2008). Psychology and religion: Classical theorists and contemporary developments. Lanham, MD: Rewman \& Littlefield Publishing Group.

Glock, C. (1962). On the study of religious commitment. Religious Education Research Supplement, 57, 98-110.

Glock, C. Y., \& Stark, R. (1966). American Piety and Anti-Semitism. Nova York, NY: Harper.

Gouveia, V. (2003). A natureza motivacional dos valores humanos: Evidências acerca de uma nova tipologia. Estudos de Psicologia, 8, 431-444.

Gouveia, V., Milfont, T., Fischer, R., \& Coelho, J. (2009). Teoria funcionalista dos valores humanos: Aplicações para organizações. Revista de Administração Mackenzie, 10, 34-59.

Guerra, V. (2009). Community, Autonomy, and Divinity: Studying morality across cultures. Tese de Doutorado, University of Kent, Canterbury, Inglaterra.

Hellern, V., Notaker, H., \& Gaarder, J. (2000). O livro das religiões. São Paulo: Companhia das Letras.

Instituto Brasileiro de Geografia e Estatística (2000). Censo demográfico 2000 - características gerais da população: Resultados da amostra. Retrieved from http://www.ibge.gov.br/ home/ estatistica/populacao/censo2000/defaulttab_brasil.shtm.

Lotufo Neto, F. (1997). Psiquiatria e religião: A prevalência de transtornos mentais entre ministros religiosos. Tese de Livre Docência. Universidade de São Paulo, São Paulo.

Maslow, A. (1983). El hombre autorrealizado. Barcelona: Kairós.

Meira, M., Gouveia, V., Socorro, T., Oliveira, S., \& Silva Filho, S. (2001). Escala de práticas religiosas: Construção e validação de construto [Resumo]. In Conselho Regional de Psicologia 13a Região PB/N (Ed.), $1^{\circ}$ Encontro Paraibano de Avaliação e Medida em Psicologia (p. 29). João Pessoa: CRP.

Mendonça, A. (1998). Religiosidade no Brasil: Imaginário, pósmodernidade e formas de expressão. Estudos da Religião, $15,39-50$.
Menéndez, M. (2007). Religiosidade e valores em Portugal: Comparação com a Espanha e a Europa católica. Análise Social, 62, 757-787.

Öner-Özkan, B. (2007). Future time orientation and religion. Social Behavior and Personality, 35, 51-62.

Pimentel, C. E. (2004). Valores humanos, preferência musical, identificação grupal e comportamentos de risco. Dissertação de Mestrado, Universidade Federal da Paraíba, João Pessoa.

Renner, W., Salem, I., \& Alexandrowicz, R. (2004). Human values as predictors for political, religious and health-related attitudes: A contribution towards validating the Austrian Value Questionnaire (AVQ) by structural equation modelling. Social Behavior and Personality, 32, 477-490.

Roccas, S. (2005). Religion and value systems. Journal of Social Issues, 61, 747-59.

Roccas, S., Sagiv, L., Schwartz, S., \& Knafo, A. (2002). The Big Five personality factors and personal values. Personality and Social Psychology Bulletin, 28, 789-801.

Rokeach, M. (1973). The nature of human values. New York, NY: Free Press.

Roof, W. (1979). Concepts and indicators of religious commitment: A critical review. In R. Wuthnow (Ed.), The religious dimension (pp. 17-45). Nova York, NY: Academic Press.

Santos, W. S. (2008). Explicando comportamentos socialmente desviantes: Uma análise do compromisso convencional e afiliação social. Tese de Doutorado, Universidade Federal da Paraíba, João Pessoa.

Saroglou, V., Delpierre, V., \& Dernelle, R. (2004). Values and religiosity: A meta-analysis of studies using Schwartz's model. Personality and Individual Differences, 37, 721-734.

Saroglou, V., \& Muñoz-García, A. (2008). Individual differences in religion and spirituality: An issue of personality traits and/or values. Journal for the Scientific Study of Religion, 47, 83-101.

Schwartz, S. (2001). ¿Existen aspectos universales en la estructura y el contenido de los valores humanos? In M. Ros \& V. V. Gouveia (Eds.), Psicología social de los valores: Desarrollos teóricos, metodológicos y aplicados (pp. 53-78). Madrid: Biblioteca Nueva.

Schwartz, S., \& Huismans, S. (1995). Value priorities and religiosity in four western religions. Social Psychology Quarterly, 58, 88-107.

Tabachnick, B., \& Fidell, L. (2008). Using multivariate statistics, $5^{\text {th }}$ ed., Boston, MA: Pearson Education.

Recebido em 22.07.2010

Primeira decisão editorial em 27.10.2011

Versão final em 30.05.2011

Aceito em 30.05.2011 